Published as 'Collective Amnesia and Epistemic Injustice' in Socially Extended Epistemology, ed. by J. Adam Carter, Andy Clark, Jesper Kallestrup, S. Orestis Palermos and Duncan Pritchard, Oxford: Oxford University Press, 2018, pp. 195-219.

Please use the published version for quotation or citation

\title{
10
}

\section{Collective Amnesia and Epistemic Injustice}

\author{
Alessandra Tanesini
}

\begin{abstract}
Communities often respond to traumatic events in their histories by destroying objects that would cue memories of a past they wish to forget and by building artefacts which memorialize a new version of their history. Hence, it would seem, communities cope with change by spreading memory ignorance so to allow new memories to take root. This chapter offers an account of some aspects of this phenomenon and of its epistemological consequences. Specifically, it is demonstrated in this chapter that collective forgetfulness is harmful. Here, the focus is exclusively on the harms caused by its contribution to undermining the intellectual self-trust of some members of the community. Further, since some of these harms are also wrongs, collective amnesia contributes to causing epistemic injustices.
\end{abstract}

Keywords

forgetting; collective amnesia; epistemic injustice; memory ignorance; intellectual self-trust

The toppling of statues memorializing Saddam Hussein by angry crowds was one of the most iconic images following regime change in Iraq. This example is not unique. Communities often respond to traumatic events in their histories by destroying objects that would cue memories of a 
past they wish to forget and by building artefacts which memorialize a new version of their history. Hence, it would seem, communities cope with change by spreading memory ignorance so to allow new memories to take root.

In this chapter, I offer an account of some aspects of this phenomenon and of its epistemological consequences. ${ }^{1}$ This chapter has three aims. The first is to show that the formation and maintenance of collective memories requires that other events are to some extent forgotten. All shared memories, including those which are shared by a large group, are the result of mechanisms that transform initially divergent recollections of the past into an agreed account. Those memories which do not survive this process so that they are excluded from the shared version become forgotten through neglect. The second is to argue that sometimes collective mnemonic silence or forgetfulness is not a mere by-product of the formation of memory. Instead, cognitive effort is specifically directed towards bringing about ignorance. Ignorance, in these instances, is a perverse kind of success. I reserve the term 'collective amnesia' for collective forgetfulness of this kind. The final aim is to demonstrate that collective forgetfulness is harmful. ${ }^{2}$ Here, I focus exclusively on the harms caused by its contribution to undermining the

\footnotetext{
${ }^{1}$ Earlier versions of this chapter were delivered in Cardiff and at the 2nd conference on Socially Extended Knowledge held in Edinburgh on 8-9 October 2015. I would like to thank the organizers of those events for the invitations and the audiences for their questions and suggestions. Special thanks to Chloe Wall, Kirk Michaelian, Duncan Pritchard and Orestis Palermos for their comments on a penultimate draft.

${ }^{2}$ It is worth noting from the start that some of the harms inflicted by collective amnesia can also result from other kinds of memory ignorance. However, ignorance which results from cognitive ability has a stability that other forms of ignorance may lack. It is therefore likely to be harder to remove. Hence,
} 
intellectual self-trust of some members of the community. Further, since some of these harms are also wrongs, collective amnesia contributes to causing epistemic injustices.

The chapter consists of seven sections. In the first I review some of the psychological literature on human biological memory which shows its outputs to be highly constructed. For this reason, biological memory is not well-suited to produce faithful and detailed reproductions of past events. It is, however, adaptive since its functions include: first, forming and strengthening social bonds; and second, laying down representations to be used to imagine future possible events for planning purposes. In the second section I focus on the first of these functions served by memory and explain how shared and collective memories are formed and sustained. In this section I highlight the selective nature of memory formation and show how mnemonic silence or forgetfulness is an essential component of the mechanisms by which a shared version of a common past is developed.

In sections 10.3 and 10.4 I lay the ground for the account, offered in section 10.5, of collective amnesia which I define as memory ignorance constituting a cognitive achievement. In section 10.3 I introduce the notion of scaffolded cognition and specifically of scaffolded memory. The term 'scaffold' is usually reserved for artefacts, strategies, modes of teaching, or environmental niches that lower the cognitive load required to carry out successfully a cognitive task and that may even extend the range of activities within the grasp of an individual. In this chapter, I advance and defend a more extended usage of the term to refer to all those environments, strategies, and devices that brace human cognition but which may increase as well as lower cognitive loads and may serve as barriers to success in some cognitive tasks. Memory

ignorance of this kind is of special interest to those concerned with addressing epistemic harms and wrongs. 
is, by all accounts, a highly scaffolded cognitive capacity; whilst the existence of scaffolds to facilitate memory is usually appreciated, the presence of scaffolds for forgetfulness is equally important. In section 10.4 I flesh out the idea that ignorance can be an achievement understood as a success due to cognitive ability. Section 10.5 provides a definition of collective amnesia as collective memory ignorance which is an achievement and supplies some examples of the phenomenon.

In section 10.6 I rely on the idea that collective memories strengthen social bonds, by providing a positive image of one's group with which one can identify, to argue that collective memories can either enhance or undermine intellectual self-trust. I also show that forgetfulness of some aspects of the shared past often functions to undermine the self-trust of some members of the community because of how they are represented (if at all) in its collective memories. Finally, in section seven I conclude that individuals whose self-trust is undermined by collective amnesia are not only harmed by it but also wronged. Hence, since intellectual self-trust is a prerequisite for the exercise of any epistemic capacity, the wrong done by collective amnesia constitutes a deeper kind of epistemic injustice.

\subsection{Human Biological Memory}

With a few exceptions, philosophers working on the epistemology of memory tend to subscribe to the so-called archival model of memory. ${ }^{3}$ According to this view we store representations of

\footnotetext{
${ }^{3}$ This model is still commonplace in analytic discussions in epistemology which assume that memory is a belief forming mechanism dedicated to secure faithful representations of past events or of previously acquired information (Martin and Deutscher 1966; Bernecker 2010). It should be noted that this model
} 
events experienced and facts learnt in the brain. These representations are memories. They are thought as beliefs and images which can be made accessible when explicitly recalled. This model has been largely abandoned in the cognitive psychology of memory. The dominant view in that discipline, a view which is supported by a growing body of empirical evidence, is that memory is largely constructed on the hoof from sketchy and selective representations (known as memory traces or engrams) encoded in the brain (Schacter et al. 1995; Schacter 2012).

The idea that memories are constructed should not be taken to mean that they are fantasies. Rather the thought is that remembering does not consist in storing beliefs and images in the mind for future, hopefully unadulterated, retrieval. Instead, relevance and context determine which representations of current experience are initially encoded. These may well include representations that are not believed or endorsed. These representations are modified in the light of background information, cognitive schemas, and heuristics as they are consolidated ready for storage. Whilst stored, representations become harder or easier to retrieve. Retrieval is facilitated when representations have been frequently retrieved before. It is inhibited by lack of past retrieval. Inhibition is exacerbated if related representations are retrieved instead. Context, current purposes, and ease of access contribute to determine which representations are retrieved at any given moment. These and other factors also determine whether the retrieved

is presupposed even by supporters of qualified generativism about memory knowledge. See Michaelian (2016, pp. 93-6) for a discussion. In the philosophy of mind, however, philosophers whose work is informed by cognitive science and other psychological disciplines have abandoned this model in favour of accounts that acknowledge the close connection between memory and imagination. See for example: Sutton et al. (2010); Michaelian (2012, 2016); and Michaelian and Sutton (2013). 
representations are endorsed as genuine memories suitable for belief formation (Michaelian 2012 and 2016).

These constructive features of the cognitive processes of memory encoding, consolidation, and retrieval help to explain several important features of human biological memory which make it very different from external memory storage artefacts such as diaries and computing devices. Human biological memories are condensed, selective, and malleable; they trade precision for accuracy but can also be inaccurate. Consider, for example, memories of summer holidays. These memories are often condensed. I spent most summers in my childhood at the seaside; when I recollect those days now, I have a generic memory of summers by the sea which is probably a condensation of many distinct events taking place over several years. My memory is selective since there is much that I do not recall. It is malleable since it has changed over the years under the influence of conversations with my sisters. Even when I have a distinct recollection of a specific event, my memory is accurate at the price of being precise. I may remember that I wore a dark jumper without remembering its exact colour. In addition, and as it is well known, our memories often betray us so that what we seem to remember turns out to be in small or large part false.

It is tempting to conclude that human biological memory does not serve us very well because it does not preserve faithful representations of the past. This conclusion would be misguided since it is predicated on the assumption that preservation of mental content is the sole function of memory. Recent work in cognitive psychology, however, strongly indicates that memory also serves altogether different purposes. One of its primary epistemic functions is to assist planning future activities (Schacter 2012). We encode representations in the brain (memory traces or engrams) in a way that makes them suitable for use when imagining possible 
future events. Of course, these can also be retrieved in recollection; but the role of these representations in imagination has determined some of their most significant characteristics (Schacter 2012).

A second primary purpose of memory is to create and strengthen social bonds. If individuals come to agree about the past, their shared recollections bring intimate couples closer together and increase the feeling of belonging in individual members of social groups. The accuracy, faithfulness, or completeness of memories do not directly contribute to its ability to fulfil this function since its goal is convergence onto a shared version of the past (which may or may not be truthful). The malleability and selectivity of memory promote agreement; they are, therefore, adaptive features even though they may undermine the reliability of this faculty. ${ }^{4}$

\subsection{Shared and Collective Memories}

This picture of the functions served by human biological memory makes sense of features of collaborative remembering which would be inexplicable if the purpose of memory were

\footnotetext{
${ }^{4}$ Michaelian (2016) argues that one should not infer from the constructed nature of episodic memory that it must be generally unreliable. This chapter is neutral on this issue. My focus is exclusively on those memories that serve primarily the function of strengthening social bonds. I argue that these memories are highly selective in ways that serve the interests of some people rather than of others. I do not claim that these memories are always inaccurate but that they are often misleading. Since episodic memories also serve other functions, no conclusion about the reliability of episodic memory in general should be derived from these points.
} 
exclusively to store and retrieve accurate representations of the past. ${ }^{5}$ Think, for instance, of school reunions, their main or sole purpose is to preserve or rekindle a social bond. When people get together during these occasions, they do catch up with each other but a lot of the time is spent reminiscing about the shared past. Since these are the events that each participant remembers, the point of the activity cannot be the transmission or creation of knowledge. Rather, the point must be to make the individuals feel closer to each other by enhancing their sense that they belong to a group whose members have things in common. This is why we are disappointed and feel left out if at these events others have forgotten what we remember. If the point of the exercise were knowledge transmission, the appropriate response would be to try to impart to others the knowledge they have lost. ${ }^{6}$

${ }^{5}$ The processes by which shared memories are formed are usually described as collaborative remembering because they are often thought as cooperative activities. Although I retain the label to indicate that I am discussing the same phenomena, my emphasis here is on the often conflictual nature of these processes.

${ }^{6}$ Of course, there may well be instances when we remember together to try to arrive at an accurate account of the past. Further, there is evidence of memory facilitation when individuals form a group to carry out a memory task. However, although members of a group recollect more relevant facts than each would in isolation, the amount of information remembered by the whole group is, because of memory inhibition, less than the sum of what would be remembered by each were they to carry out the memory task in isolation. Thus, if we wanted to maximize memory we should ask people to remember in isolation a different part of a task and then collect their individual memories to obtain their sum. See, Hirst and Echterhoff (2011) for the phenomena of inhibition and facilitation. 
Collaborative remembering is one of the main mechanisms by which all close personal relations are formed, sustained, and enhanced. For this reason, couples and close friends or family members spend a lot of time sharing memories of past experiences. Recollecting together strengthens social bonds in several ways. Firstly, it makes salient that past which one has in common with some others. This idea of a common feature- be it a past, or a preference, or a point of view - is sufficient to engender a sense of belonging to a group. But, secondly, shared memories are particularly apt at facilitating the creation of strongly bonded groups based on shared identities. In the same way in which autobiographical memory plays a crucial role in an individual's self-conception, memories of a common past often contribute to thinking of some social group, to which one belongs, as defining of one aspect of one's identity. Thus, one way of strengthening the sense that a given social group is defining of who one is, is to feel that the memories of the group's past are the memories of one's past, which one shares with other members of that identity defining group.

This shared past, which brings people together, however, is to a significant extent constructed through the process of collaborative remembering. As I explained in section 10.1, constructed memories are not mere fantasies, they are however selective and condensed. These features also pertain to shared memories whose construction is the outcome of social processes shaping initially divergent individual memories so that they converge towards one version of the past which subsequently is remembered by each person involved.

Recent empirical studies on intimate couples who have been together for a long time show that their collaborative remembering can display features that are characteristic of transactive memory systems (Sutton et al. 2010). A transactive memory system is a dynamic system that includes memory sub-systems (such as an individual's memory) and the processes by which 
these communicate. Since its component sub-systems are socially coupled and exhibit continuous reciprocal causation, the system as a whole acquires a range of emergent properties (Wegner 1987; Tollefsen, Dale, and Paxton 2013). Some of these features are present when couples engage in free-flowing conversation about their past (Hirst and Echterhoff 2011).

For example, each member of the couple continuously supplies cues to the other in conversation. This cross-cuing activity enhances individual memory by facilitating the recall of memories which the person would not have retrieved un-prompted. Other mechanisms are responsible for mnemonic convergence so that the memories of each member of the couple are eventually in broad agreement with those of the other to form a shared version of their past. The most extensively studied mechanism, among these, is known as socially shared retrieval induced forgetting (hereafter, SS-RIF) whose effect have been robustly demonstrated in the cognitive psychological literature (Stone et al. 2012; Hirst and Manier 2008).

Early studies show that in laboratory conditions the explicit retrieval by a person of some semantic information makes in the short term semantically related but unretrieved information harder to remember than what is equally unretrieved but bears no semantic connection to the retrieved information. In the standard experiment participants are presented lists of categoryexemplar pairs such as animal-cat; animal-dog; vegetable-spinach; vegetable-broccoli. They are made to practise retrieving some cued pairs and not others by being asked to complete them: animal-d___, for example but not animal-c___ or vegetable-s__. A retrieval induced forgetting effect is found if pairs (such as vegetable-spinach) which have not been practised but are not semantically related to the practised pairs are better remembered than those pairs which have also not been practised but are semantically related to the practised pairs (animal-cat, for instance) (Coman, Manier and Hirst, 2009). 
The studies on the reminiscing of couples in conversations have shown that the same effect can be observed when the memories concern autobiographical events rather than semantic information, when remembering is done in spontaneous conversation rather than prompted in a laboratory, and that the effect is socially shared so that it is observed both in the person who explicitly retrieves a memory, but also in the other partner who at that point is listening (Coman and Hirst 2012). Thus, when a person mentions in recollection some features of a past event but is silent about others, the neglected aspects have become, for both participants in the dialogue, harder to recall than other events which were not the topic of conversation.

Although the lesson learnt from the study of autobiographical memory in individuals, dyads, and small groups cannot be automatically applied to larger groups, there is sufficient evidence to support the view that communities also share enduring memories (including of events that current members have not directly witnessed) which are part of the group's identity. ${ }^{7}$ These memories are generally called 'collective memories' (Hirst and Manier 2008; Stone and Hurst 2014). For instance, memories of heroism and pointless death during World War I, of Scott's tragic polar expedition, or of warm beer and games of cricket have all become part of the collective memory of the British people. Collective memories are also largely constructed by processes of collaborative remembering which select events that are defining of the group's identity and may mark turning points in its history. They contribute to sustaining the idea of a national character and to determining its features. In Britain, these include, for instance: self-

\footnotetext{
${ }^{7}$ Hence, collective memories are generative of content since they enable individuals to have quasiautobiographical memories of events which they did not personally experience. Consequently, there is a tendency in some research on the topic to include the whole recorded history of a group among its collective memories.
} 
sacrifice, courage, fair-play, being a good loser, and a spirit of adventure. Collective memories, hence, set out what it takes to be part of the group, strengthen a sense of belonging in those who feel represented by them, and, since they are often positive, enhance their self-esteem. Collective memories may also comprise memories of events that mark some groups of individuals as outsiders or even enemies. In Britain one is reminded of the enduring salience of memories of World War II every time the English football team is scheduled to play against Germany.

Collective memories are transmitted from generation to generation through social learning (Sutton 2016). They are also continually formed and transformed through experience. These processes of formation and transformation include mechanisms which lead to mnemonic convergence of initially disparate individual memories. One such mechanism is social contagion, which occurs when a fabricated 'memory' or misleading information is implanted in unsuspecting listeners (Hirst and Manier 2008). Contagion may involve post-event misinformation effects when witnesses, who have first-hand experience of an event, claim to remember what is in fact misinformation which they have been fed after their experience (Loftus 2005). ${ }^{8}$ Social contagion is not rare and does not occur only when the misinformation is impersonally presented. Speakers can impose a new memory on their listeners; the effect is especially strong when one person arrogates for herself or himself the role of narrator and thus succeeds in monopolizing the conversation (Brown, Coman, and Hirst 2009). Further, people who are perceived as experts by their audience, and socially powerful individuals can more easily implant new 'memories' in their listeners than those who lack status or are not thought to have expertise (see Hirst and Echterhoff 2011 for a review).

\footnotetext{
${ }^{8}$ Such misinformation may include complete fabrication.
} 
In addition to social contagion, memories converge among members of a group because of re-exposure and retrieval effects. Repetition of known memories facilitates future remembering especially for the speaker who recounts the events (Hirst and Echterhoff 2011). Further, since speakers often tune their messages to the attitudes they attribute to their listeners, the audience can indirectly affect what a speaker will in future remember. For example, speakers may be discerning about how to phrase a potentially ambiguous point, such as describing a person as stingy or as being careful with money. Since re-exposure facilitates memory, unsurprisingly researchers have found that speakers subsequently tend to remember events in the terms in which they have presented them to their audience (this is known as the saying-is-believing effect) (Hirst and Echterhoff 2011).

Best known among the retrieval effects is induced forgetting. I have already discussed the phenomenon above with regards to dyads and small groups. There is now empirical evidence that its effects can be propagated throughout a group to individuals who are only indirectly related to the original speaker or speakers (Yamashiro and Hirst 2014). ${ }^{9}$ Further the effect is present when one person addresses a large audience (Stone and Hirst 2014). Several factors mediate the presence of SS-RIF but their interaction is not well-understood. It is generally accepted that the mechanism underlying SS-RIF is covert retrieval, alongside the speaker, of the explicitly mentioned memories. If this account is correct, it would explain why no effect is found

\footnotetext{
${ }^{9}$ Thanks to Kirk Michaelian for pointing out that these results underplay the role of conflictual processes in memory formation. The focus on memory convergence in small groups has led researchers to focus on collaboration. But the same degree of cooperation cannot be attributed to members of larger groups. My discussion of collective amnesia in section 10.5 below illustrates some of the ways in which memory convergence occurs in conflictual contexts.
} 
when the audience does not pay close attention to the speaker or does not identify with him or her. In the first case members of the audience may not retrieve any representations; in the second listeners, who are critical of the speaker, may well remember other things he or she has left unmentioned (Stone and Hirst 2014). ${ }^{10}$ The account cannot equally accommodate other surprising results. In particular, it cannot easily explain why, provided that the audience largely agrees or identifies with the speaker, SS-RIF is inversely related to perceived expertise and trustworthiness. That is to say, SS-RIF effects increase when the audience perceives the speaker to be untrustworthy or not to be an expert (Koppel et al. 2014; Hirst and Echterhoff 2011).

In sum, the empirical evidence reviewed in this and the preceding section indicates that collective memories can contribute to strengthening social bonds by shaping shared group identities. The evidence also indicates that collective memories are formed by mechanisms of selection and construction which, because of SS-RIF effects and of social contagion, facilitate the convergence of previously divergent memories onto a shared-possibly fabricated—version of the past. Other aspects of the past, which were initially remembered by some individuals, are instead crowded out and become almost unretrievably forgotten.

\subsection{Scaffolded Cognition}

\footnotetext{
${ }^{10}$ In Belgium, the French-speaking audience exhibited SS-RIF effects after listening to a bilingual prerecorded speech by the king, whilst the Flemish-speaking audience did not. Since the king is more closely associated with the French-speaking community, the authors of the study speculated that Flemish-speaking listeners either did not pay attention or were sceptical about what the king said and thus covertly retrieved different memories (Stone and Hirst 2014)
} 
In section $10.2 \mathrm{I}$ have explained that human biological memory is malleable and subject to modification by means of social influences. These facts are no surprise given that memory is an instrument for the enhancement of social bonds. In this section I first outline the concept of scaffolded cognition before showing that human memory is often scaffolded. I also argue that scaffolding does not always serve the purpose of facilitating cognition, it can also work to inhibit it. In other words, ignorance as well as knowledge can be scaffolded.

Scaffolded cognition is cognition which relies on scaffolds, where a scaffold is somethingtypically outside the skin of the cognizer — that shapes, structures, or directs cognition. ${ }^{11}$ Scaffolds are usually thought to facilitate the successful completion of cognitive tasks by lowering the cognitive load they require or by allowing the cognizer to succeed in tasks which he or she would be unable to perform without support (Kirsh 1995; Sterelny 2007, 2010). ${ }^{12}$ Scaffolds vary both in their nature and in the manner in which they facilitate cognition. They include other people (such as teachers), epistemic technologies (such as notebooks, maps, and charts, or pen and paper), and modified environments constructed to serve as informational niches (such as the files in an archive or tools in a workplace). They facilitate cognition by simplifying choices, by transforming hard problems into perceptual tasks that are easier to solve,

${ }^{11}$ Some supporters of scaffolded cognition present the view as an alternative to the claim that the mindand therefore knowledge and cognition — can be extended outside the body (Sterelny 2010). In this chapter my adoption of the view that cognition is scaffolded is not to be taken as a rejection of the possibility of extended minds.

${ }^{12}$ For a history of the study of scaffolding in cognition and for a careful taxonomy of the various meanings of the term in different areas of study, see Sutton (2016). The notion has played an especially significant role in education theory. See van de Pol et al. (2010) for a review. 
and by directing learning. For instance, pen and paper and the use of the carrying procedure are a great help when doing long additions. The task can be simplified further by being turned into the perceptual and motor task of punching the numbers into a calculator and reading off the result.

The construction of informational niches that facilitate problem solving is not always an intentional process, since space can be structured to support cognition through a process of coadaptation. Two brief examples illustrate the point. First, niches can be brought into existence by purely stigmergic behaviour (a kind of indirect coordination). For instance, navigation from location A to location B is made easier when repeated walking between the two places creates a path. Thus, a task which may have previously required a map and/or local knowledge is transformed into the essentially visual and motor task of following the path (Marsh and Onof 2008).

Second, Internet search engines offer a different—more complex — but instructive example. Search strategies adopted by users and the development of algorithms for the engine are the outcome of mutual adaptation. Search engines facilitate the task of finding relevant information of decent quality. They are essential since the Internet is a highly epistemically polluted environment which comprises an enormous amount of information that is of mixed quality and unsorted for relevance. Once search engines became available, users started to use them in a new way. Instead of searching for information resources such as websites, they begun to rely on the engines directly to find answers to questions.

This change in search strategy is predicted by information foraging theory which states that, whenever access to information is made easier, individuals begin to visit more sites and spend only sufficient time on each to extract a nugget of relevant information (Taraborelli 2008). The information hunter, according to this theory, does not commit to reading carefully any one site in 
search for highly reliable and relevant information since she may emerge empty-handed. Instead, she adopts the less risky strategy of accepting many bits of information of lesser relevance and reliability which she can more easily acquire through moving from site to site.

The algorithms of search engines are constantly refined in response to users' behaviour to facilitate their foraging. Individuals rarely make independent assessments of the quality and relevance of the information provided by websites. Instead, they rely on cues (information scent) which are detectable without accessing them. Such cues range from "likes" on social media to rankings offered by the engine. Since these are reputational markers, they are usually indicative solely of popularity and bear no connection to quality or reliability. ${ }^{13}$

The co-adaptation of search engines and Internet users' foraging behaviour offers an example of scaffolding that facilitates both knowledge and ignorance. Without search engines, it would be almost impossible to acquire new knowledge from the Internet. These engines are therefore scaffolds that have expanded the range of users' problem-solving ability. However, the benefits offered by the engines have come at a price because the quality and accuracy of information is compromised in the service of speed.

The idea that tools that support cognition can inhibit knowledge rather than promote it has, as far as I am aware, gone unnoticed so far. Yet, for instance, there are environments which are designed to make successful searches more cognitively demanding by transforming what would be a memory task into a visual search task within an environment where the target object is not prominent. Retail space is a revealing example of an environment which is deliberately designed

\footnotetext{
${ }^{13}$ Since each "like" or preference is not expressed independently of others but in the knowledge of what has proven popular to date, there is no reason to think of this case as an example of the so-called wisdom of the crowd.
} 
to make knowledge harder to gain. The big supermarket chains develop planograms detailing where to place various kinds of produce on their shelves. Their main aim is to make you spend as much money as possible. To achieve this goal, they invite you into the shop where they slow you down and make you traverse as much of the floor space as possible. Numerous techniques are deployed to achieve these objectives: shuffling the products around is one of these. Since the location of the product on the shelves is changed on a regular basis, it is impossible for the customer to grab and go. Instead, one must search extensively for what one wants so that one will also come across other items which one may impulsively buy. The shopper's increased cognitive load is a success for the planogrammer, since it is the means by which his or her aim of making the shopper see as much of the produce as possible is achieved.

The literature on scaffolded cognition has not paid sufficient attention scaffolding for ignorance because of its focus on adaptation and cooperation. However, adaptation often leads to satisficing rather than optimizing strategies which may well compromise quality for speed. In addition, human behaviour is not always cooperative. Instead, some agents may pursue their selfinterest to the detriment of other individuals. Sterelny has referred to cases such as these as examples of informational niches as 'contested spaces' in which epistemic tools may increase rather than decrease cognitive load. He acknowledges the existence of the phenomenon but thinks of it as relatively rare (Sterelny 2010, 474). I disagree since I believe that most public spaces are in part contested since power relations are omnipresent.

Be that as it may, for my purposes here the significant point is that a scaffold is an epistemic tool, such as a notebook, or an informational niche (like a path or a classroom or a supermarket) which modifies and structures cognition. These have developed by adaptation and design and are often shared. We should thus expect scaffolds both to facilitate and hinder cognition. First, the 
contested nature of space means that some may litter it with misinformation and other forms of epistemic pollution as an obstacle preventing others from gaining knowledge. Second, the shared nature of epistemic tools requires standardization so that they may fit better the needs of some epistemic agents rather than those of others. ${ }^{14}$ Third, adaptation typically results in compromises thus one should expect trade-offs where epistemic goods are gained at the expense of the loss of others. These features of the processes involved in the construction of informational niches and the production of epistemic tool suggest that we gain a better understanding of the phenomena involved if we adopt the label 'scaffold' to refer to bracings of cognition that enable it, but also to those which hinder it, since in many instances one and the same item has both effects.

Memory is perhaps the most scaffolded among human cognitive activities. We seem to have learnt a long time ago to offload the task of retaining accurate information about the past to external devices such as diaries and record books. Thus, whilst discussions as to whether the mind is extended to include epistemic technologies within its boundaries tend to focus on the similarities between biological memory and technology-enhanced memory, what is perhaps most striking is how different the two kinds of memory are from each other (Sutton 2010). We rely on external information storage devices so much precisely because they have features that human brains lack. They are designed to store a vast amount of information, in a way that is almost permanent and whose retrieval is unconstrained (Donald 1991). Of course, the cleverer humans have become at creating such storing devices the less they need to retain information within their biological memories. However, this process of offloading information has also increased the need to learn how to access it without being overwhelmed by epistemic pollution (Sterelnyi

\footnotetext{
${ }^{14}$ Otto's highly individual notebook is in this regard not typical of epistemic tools (Sterelny 2010).
} 
2007: 218-19). The outcome is a trade-off between cognitive load and quality of information in terms of accuracy and relevance.

The scaffolding of biological memory does not consist exclusively in the creation of devices for external storage; we have also structured physical spaces to facilitate the making and the retrieval of memories. For instance, the sole purpose of so-called mementoes is to cue the recall of special events or people in our lives. We have invented mnemonics that cue semantic memory. Thus, we use the knuckles in our hands to remember which months have thirty-one days. We also organize our living environment to make remembering easy. We tend to keep things in the same place, pin reminders to places like the fridge door where we regularly see them. Another way in which we scaffold human memory is by creating bodily habits and rituals whose purpose is to facilitate carrying out daily routines. For example, we celebrate anniversaries and birthdays to make and retrieve memories of our lives and of those of significant others.

The mechanisms of social contagion, and the effects of repetition and retrieval described in section 10.2 above can also be understood as scaffolding shared memories. They assist their formation, but they facilitate this task at the cost of accuracy and comprehensiveness, since they assist the implantation of false memories and promote the forgetting of selected aspects of the past. Thus, the scaffolding of human biological memory facilitates both memory knowledge and memory ignorance.

\subsection{Ignorance as an Achievement}


There is a large and growing literature in analytic epistemology on knowledge as an achievement due to cognitive ability (Pritchard 2009; Sosa 2007; Greco 2012). ${ }^{15}$ Intuitively, however, ignorance is also something that can be credited to the cognitive efforts of epistemic agents. Thus, the example above concerning shelving in supermarkets, for instance, illustrates that one person's ignorance can be another's success. In this section I offer an account of what it takes for ignorance to be an achievement. I use the label 'strong ignorance' to refer to this kind of ignorance. The term is apt since this is an epistemic bad which is generally harder to remove than ordinary ignorance. ${ }^{16}$ In what follows I first provide the foundations of a theory of ignorance as the opposite of knowledge-wh, rather than of propositional knowledge. Second, I argue for some further conditions which are necessary for an instance of ignorance to be also an achievement. These conditions are closely related to those which must be fulfilled if a true belief is to count as propositional knowledge. I conclude the section by mentioning three families of cases where ignorance is an achievement: self-deception and wishful thinking; deception and the transmission of misleading information; cognitive states formed within an informational niche which, by design or adaptation, increases cognitive load.

Until recently the nature of ignorance was a much neglected topic in analytic epistemology. Instead, ignorance was often presumed simply to be the contradictory of propositional

\footnotetext{
${ }^{15}$ In this literature there is a lively debate on how to spell out the senses in which the success is due to the cognitive ability. Greco (2012) offers a clear summary of some of the existing options.

${ }^{16}$ I take my notion of 'strong ignorance' to be of a piece with the notion discussed in the so-called epistemologies of ignorance (Mills 2007; Tuana 2004 and 2006; Dotson 2011). My account differs from theirs in several respects. Most significantly, I do not offer a consequentialist analysis of the difference between mere and strong ignorance.
} 
knowledge. As Rik Peel $(2010,2011,2012)$ has convincingly argued this view is incorrect since the person who has a true belief based on a hunch lacks propositional knowledge but is not ignorant. However, the possibility that ignorance may be the contradictory of knowledge-wh (which, where, what, who) has not been addressed in the existing philosophical literature. A full defence of this position is beyond the scope of this chapter; in what follows I limit myself to offering some considerations in its support.

Firstly, and most superficially, attributions of ignorance in the English language share some of the syntactical constructions of knowledge wh- attributions. For instance, one may be said to be ignorant of the effects of exposure to radiation or to know what they are. Both constructions can take a noun phrase (e.g 'the effects of exposure to radiation') or a sentential complement (e.g., 'what the effects of exposure to radiation are'). Attributions of propositional knowledge are different since they consist of verb + that + sentence. Secondly, ignorance attributions appear to be close in meaning to denials of knowledge wh-. Thus, a person who is ignorant of something is someone who does not know what that something is. Someone who is ignorant of her location is someone who does not know where she is. Thirdly, attributions of knowledge wh- and of ignorance exhibit the same kind of context-sensitivity. It has been noted that a person who has just landed at Heathrow airport, may be said to know where she is, even if all she knows is that she is in London. In this instance, it is natural to think that she is not ignorant of her location. However, one would also be inclined to say of that same person, once a taxi drops her off somewhere in the City, that she does not know where she is, although she still knows that she is in London. In this instance one is also prepared to attribute to her ignorance of her location. Since the context-sensitivity of knowledge wh- has often been cashed out in terms of relativity to 
the informational needs of the attributor, there is a prima facie case for adopting the same position about attributions of ignorance. ${ }^{17}$

One attributes knowledge of her location to the person who has landed at Heathrow because she possesses an adequate answer to the question 'where are you?' which is embedded in the knowledge attribution. The answer 'I am in London' is true and is also serviceable as an answer since all the attributor plausibly wishes to know is the name of a city. However, when one asks whether a person, who is somewhere in the City, knows where she is, one is asking whether she knows where she is in relation to other destinations in London; one is not asking whether a person knows that she is in London rather than in Paris. Plausibly, the same considerations apply to attributions of ignorance, since we ascribe ignorance to those who cannot easily provide adequate answers to our questions, where an answer is adequate when it is both true and

\footnotetext{
${ }^{17}$ There is a lively debate on how attributions of knowledge wh- should be understood. I shall not address it here. However, it is generally assumed that knowledge at least requires possessing a true belief which answers the question embedded in the attribution. It is also agreed that they are context sensitive. For a review, see Parent (2014). I owe the idea that the correctness of knowledge attributions may depend on the local and global informational needs attached to the attributor's practical tasks to Greco's (2012) discussion of propositional knowledge as true belief which is a success attributable to ability.
} 
serviceable given the questioner's informational needs attached to the actual (or potential) practical task at hand. ${ }^{18,19}$

In sum, ignorance is best understood as lack of knowledge wh-, which in turn can be understood as follows:

$\mathrm{S}$ knows wh-Q only if $\mathrm{S}$ believes (or could easily believe) that $\mathrm{p}, \mathrm{p}$ is true, $\mathrm{p}$ is an/the answer to the embedded question Q given the informational needs of the inquirer attached to actual or potential practical tasks in the context of attribution. ${ }^{20}$

Ignorance therefore is defined in the following terms

${ }^{18}$ These considerations should not be taken to imply that contrastivism is true of ignorance ascriptions. The relativity to context may be a pragmatic phenomenon rather than a semantic one. The same debate emerges regarding knowledge wh- attributions (Parent 2014).

${ }^{19}$ It might be argued that the example relies on an equivocation about location. The person, who knows that she is in London but has no more detailed knowledge of her thereabouts, would be ignorant because she does not possess a true belief about her exact location. Thus, this example could be explained by the view that ignorance is absence of true belief (cf. Peels 2010). However, note that even a person who knows her exact coordinates may be said to be ignorant of her location if she does not know where the place she occupies is in the relation to her destination. It is not plausible to think a specification of location must also detail its relations to all other places. It is more plausible to explain these cases by taking ignorance ascriptions to be context relative in the same manner as knowledge whattributions. Thanks to Duncan Pritchard for the objection.

${ }^{20}$ Sometimes we attribute knowledge wh- to people who do not have, but are able quickly to find out, the information required to answer the embedded question. See Farkas (2016). 
$\mathrm{S}$ is ignorant of the answer to $\mathrm{Q}$ if it is not the case that $\mathrm{S}$ believes (or could easily believe) that $\mathrm{p}, \mathrm{p}$ is true, an/the answer to the embedded question $\mathrm{Q}$ given the informational needs of the inquirer attached to actual or potential practical tasks in the context of attribution.

Armed with this account of ignorance as what is ascribed in attributions of ignorance we can begin to home onto the narrow subset of examples of ignorance which are also an achievement. This is the kind of ignorance which I have stipulated to label 'strong ignorance'. We may approach it by noting that ignorance can be the result of bad luck, it can be a mistake due to an occasional or persistent malfunction of a cognitive process, or it can be the outcome of cognitive activity functioning well. First, ignorance may be caused by bad luck. For example, a person may not know where she is because the compass on which she relies is broken. Alternatively, an individual in a dark room may be ignorant of what is in front of his eyes even though he has twenty-twenty vision. ${ }^{21}$

Second, ignorance may be the outcome of failing cognitive faculties. For instance, one may be ignorant of the sum of two numbers because one has made an adding mistake. One may be unable to remember what one had for dinner the night before because one's short-term episodic memory is impaired due to the aging process. These are cases of cognitive malfunctioning which lead to ignorance.

${ }^{21}$ These two examples may be analogous to the two kinds of good luck—intervening and environmental - that can conspire to give rise to a true belief which is not knowledge. See Pritchard (2009) for the distinction between two kinds of luck. 
But, third, ignorance may also result from cognitive activity which is functioning normally (and is not affected by bad luck). To appreciate why ignorance may be produced in this manner, it is useful to consider both the practical and informational needs that an actual or potential inquirer may have. In what follows I use the term 'attributor' for the person who attributes ignorance to a person and 'attributee' for the person to whom ignorance is attributed. In cases of self-attribution, the attributor and the attributee are the same person.

Plausibly, every human being has a standing global informational need that others are good informants. Thus, every attributor needs any attributee to know the answers to all questions. This is true even if the attributor knows the answer to a given question and thus does not need to be told. It is still in her interest that other people also know the answer since such knowledge may be necessary if they are to serve as informants on other matters of which the attributor has no knowledge. However, an attributor may also have practical needs which are driven by goals that do not concern the acquisition of accurate information. For example, he may need to keep some attributee ignorant. The attributor may have hidden something which he does not want anybody to find. An attributor can thus have a practical need that others do not know the answer to a question despite also possessing a standing informational need that they do. To this end, she may mislead other people so that they are ignorant of the relevant answer. Their ignorance is not mere bad luck; it is also not the product of a cognitive error or malfunction. Rather, they have been deprived of the means to acquire the necessary information.

I am now able to explain what it means to say that some ignorance is an achievement. My account is based on the intuition that epistemic bads, as well as epistemic goods, can have this status since achievements are successes that can be credited to someone because they are the product of their abilities. Strong ignorance, is characterized as follows: 
$\mathrm{S}$ is strongly ignorant of the answer to $\mathrm{Q}$ only if (a) $\mathrm{S}$ is ignorant of the answer to $\mathrm{Q}$ and (b) S's ignorance is a success which is creditable to S's cognitive ability.

Before explaining each element of this characterization, it might be helpful to offer an example. Suppose that I think that my professional career is a success. I may, when wondering how it all came about, form the view that my achievements are exclusively the product of my own hard work and talent rather than partly of white privilege. ${ }^{22}$ Suppose that this answer to my own question is false, but I need to believe it. Perhaps I would find it hard to maintain self-confidence in the absence of this comforting thought. I could not, of course, sustain the conviction if I realized that it is the product of wishful thinking. Thus, I must form my opinion by considering evidence, rather than plucking the answer out of thin air. In truth, the desire to believe that I owe my success exclusively to my efforts biases the formulation of the hypotheses about the causes of my success and the selection of the considered evidence. I may reason correctly given the evidence that I bring to bear on the case, but I ignore other evidence that supports a different conclusion. $^{23}$

This example illustrates what is generally known in the psychological literature as goaldriven motivated cognition (Kunda 1990). Cognitive activity is effortful, so motives are required

\footnotetext{
${ }^{22}$ If you do not find it plausible that people who think this are engaging in self-deception choose the less controversial example of the person who thinks of her first born that she is the smartest kid in her class despite evidence showing that her abilities are average.

${ }^{23}$ An opinion formed because of self-deception may nonetheless be true. When this happens one may not be ignorant. But note that we are prepared to say that someone, who guesses the right responses in a quiz, knows the answers. Guessing right or hitting on the right answer, despite engaging in wishful thinking, may result in knowledge wh- rather than in ignorance.
} 
to initiate it. At times, it is occasioned by a desire to acquire accurate information; at other times, practical needs such as the preservation of self-esteem are the main drivers of cognitive activity. When these practical considerations motivate cognition, such activity is said to be goal-driven as in the case of wishful thinking.

My ignorance in this example would fit the characterization of strong ignorance. First, the belief is a case of ignorance given that it is false (and therefore not an adequate answer to the question). Second, the belief is a success which is creditable to my cognitive ability. The belief is a success because it is the outcome of cognitive activity which, in producing it, achieves my overall aim. Thus, in the same way in which true belief counts as a success when it is the outcome of accuracy-driven motivated cognition, false beliefs which enhance self-esteem can be the product of successful goal-driven cognition. ${ }^{24}$ Further, the success of the belief (its capacity to enhance self-esteem) is to be credited to my competence. It is because I reasoned and considered evidence that I can sustain the ultimately false belief. Goal-driven motivated cognition is a cognitive ability whose aim is to achieve the goals that drive it. In this case it functioned well and it is because of its good functioning that the successful belief was its product. In sum, my ignorance is an epistemic bad that is creditable to me in the sense of being something that I have achieved.

Using this example as a springboard, I am now able to spell out in more detail what it means for a state of ignorance to be a success which is due to cognitive ability. The person who is ignorant does not have an adequate answer to a question. The question is implicit in the attribution of ignorance; one lacks an adequate answer when one does not possess an answer

\footnotetext{
${ }^{24}$ See Sosa 2007 for the view that accurate belief is successful belief.
} 
which would satisfy the informational needs of the attributor. Since standing informational needs are global, a false answer is never adequate. Ignorance, however, does not require that one has false beliefs. One may be ignorant because one has a true belief which is not an adequate answer to the question at issue. Alternatively, one may simply have no opinion.

The attributor of ignorance, however, also has further practical needs which are not related to the need for accurate information. The state of ignorance is a success when it satisfies a preponderance of these practical needs. In the example above the belief is a success because it satisfies the need for self-enhancement. When I asked myself a question about my professional career, I aimed to have an answer that raised my self-esteem, my putative answer in so far as it achieves that goal is a success. ${ }^{25}$

The success is due to competence or cognitive ability (as opposed to luck) whenever two conditions apply. First, the resulting state of ignorance is an outcome of cognition functioning well in the sense of achieving its aim. Both temporary error and more permanent impairment are absent. Second, the telling contribution to the success is the contribution made by those functioning cognitive abilities. More undoubtedly needs to be said about the idea of a telling contribution. However, we can get to grip with the notion by way of an analogy discussed by John Greco (2012). He notes that in football, goals are ascribed to the players who put the ball into the net, even though their contributions may have been less skilful than those of the team mates who made the assist. The achievement is credited to the goal scorers because it was their

\footnotetext{
${ }^{25}$ More needs to be said to justify the claim that ignorance attributions are relative to the needs of the attributor rather than those of the attributee. The argument is like those made in accounts of knowledge wh- attributions.
} 
contributions that made the difference to the score and thus made the whole action a success. ${ }^{26}$ In the example discussed here, the belief is a success because it satisfies the attributor's need for an answer that enhances self-esteem. The success is due to cognitive ability because (a) it is the outcome of cognition functioning well, and (b) it is the contribution of this cognitive activity makes it the success it is (since a comforting thought plucked out of thin air would not have sustained conviction).

Deception and the offering of misleading information are also paradigmatic examples of strong ignorance. On these occasions the people who are ignorant (attributees) and those who ascribe ignorance to them (attributors) are distinct. For instance, imagine that the spokespeople for a tobacco corporation intend to spread doubt about the health effects of smoking to counter messages that it causes cancer. These individuals point to evidence that raises questions about the validity of studies that link smoking to cancer. In this manner, they may succeed in throwing some people into a state of doubt. By supplying misleading (but perhaps true) information the representatives of the tobacco industry have induced a state of ignorance in some consumers. It is obvious that those who doubt do not possess an answer to the relevant question about the causes of cancer that would address the global standing needs for accurate information that even public relation executives possess. Thus, the consumers are ignorant. However, their ignorance is a success given the practical needs of the representatives of the tobacco industry that people continue smoking. Further, it is a success which is in part due to propaganda. Thinking,

${ }^{26} \mathrm{My}$ view of strong ignorance as a success attributable to cognitive ability is heavily indebted to Greco (2012) where he argues for an account of knowledge in these terms. He also cashes out attributability as a pragmatic relation that holds between the state that is a success and those elements among its causes that made it a success. 
reasoning, and in general a lot of cognitive effort went into devising persuasive messages. Therefore, among the causes of the successful state of doubt are the well-functioning cognitive activities of the individuals who spread misleading information. However, the person who is misled also engages her cognitive faculties when reaching the state of doubt. She considers the misleading evidence, she evaluates it, and thus she withholds belief. Perhaps, she rationally revises her previous view about the carcinogenic properties of cigarette smoke. It is her contribution to the production of doubt which is telling in making it a success, since she now believes that there is insufficient evidence to form an opinion. It is her conviction that doubt is the rational position grounded on her exercise of her cognitive activities that makes it such a success for the tobacco industry, since it gives her reasons not to make further inquiries. ${ }^{27}$

A third kind of strong ignorance is exemplified by cognitive states formed in informational niches which, by design or adaptation, increase cognitive load. I have already illustrated this phenomenon in my discussion above of how supermarket shelves are stacked to inhibit knowledge of the location of products. In this example the practical needs of the planogrammer are satisfied when the ignorant consumer is aware of her ignorance and therefore continues searching. Hence, the consumer's ignorance (combined with her awareness of it) is a form of success. Further, what makes it such a success is in part the design of the informational niche which is tailored to the production of ignorance. However, the telling contribution is made by the

\footnotetext{
${ }^{27}$ We may say that the misled individual is not aware of her ignorance. The presence of higher order ignorance is a feature of some of the cases discussed here. However, it is possible to suffer from strong ignorance and to know it. It is also possible not to know that one is ignorant, when one's ignorance is solely due to bad luck.
} 
shopper's cognitive capacity to appreciate her ignorance since it is this awareness that prompts her to search the shelves further.

\subsection{Collective Amnesia}

In section 10.2 I have reviewed some of the processes by means of which individuals' memories converge to become shared memories. This discussion highlighted the fact that forgetting is an essential part of how shared memories come to be formed. In this section I return to those processes to show that, in some cases at least, they involve a kind of forgetfulness that exhibits the features characteristic of strong ignorance as defined in section 10.4. I reserve the expression 'cultural amnesia' for strong collective memory ignorance. In this section I offer an account of this phenomenon using some hypothetical but plausible examples by way of illustration. I show that social contagion, re-exposure and retrieval effects often exemplify the dynamics which I singled out in section 10.4 as contributing to the formation of strong ignorance. Here, I present memory analogues of wishful thinking, misleading, and deceiving, and memory niches which increase the cognitive load required for some kinds of recollecting. In the next section I argue that collective memories can enhance the intellectual self-trust of some members of the group, whilst the self-trust of others is undermined by collective amnesia.

I do not take 'memory' here to be factive. Thus, I include among memories all those representations both accurate and inaccurate which are at least available for retrieval by some individual member of a group. Memories may be endorsed as beliefs or discarded upon retrieval as inaccurate. Collective memories, as described in section 10.2, are memories which contribute to defining the identity of a group. They are enduring because they are endorsed as beliefs; they are shared because they are common to most members of the group. 
The first kind of strong memory ignorance has been studied with regard to individual memory but may generalize to groups and their collective memories. It is a form of selfdeception or wishful thinking in the service of self-flattery. There is evidence that individuals' autobiographical memories tend to show self-serving biases. These biases correlate positively with levels of self-esteem so that those whose self-esteem is high are more biased than others (Tafarodi, Marshall, and Milne 2003). The more likely explanation for this outcome is a combination of two factors. First, people recall more fluently than other behaviours those actions which exemplify traits predictive of success (Sedikides and Gregg 2008). Presumably, this tendency is more prominent in individuals whose self-esteem is high. Second, humans have the propensity to treat fluency in recall as a proxy for accuracy, so that memories that are fluently recalled are likely to be endorsed and therefore believed (Michaelian 2012 and 2016).

These self-serving memories are an example of strong memory ignorance. They are an instance of ignorance because of their inaccuracy. These states of ignorance are achievements because each is a success due to cognitive ability. These memories are a success because they satisfy the need to sustain self-esteem by forgetting less flattering aspects of past. Selfenhancement is presumably the motive driving cognition in these cases. In addition, the goal is achieved thanks to mnemonic cognition functioning well since fluency in recall is an indicator of validity.

These considerations suggest that those individuals who, because they have high selfesteem, are likely to speak up on behalf of groups are also the most likely to be ignorant of aspects of their autobiographical past which are incongruent with their self-concept. Since individuals with higher socioeconomic status tend to have higher self-esteem (Twenge and Campbell 2002), those who have the means and the confidence to shape public discourse about 
the past, are precisely the same individuals whose memories are more profoundly shaped by selfserving biases.

The second kind of strong memory ignorance derives from the psychological mechanisms which facilitate the convergence of memory by promoting the acquisition of some memories and inhibiting the retention of others. In section 10.2 I have singled out social contagion and retrieval effects such as SS-RIF which cause initially divergent memories to converge into one shared memory. Very often these mechanisms function in ways that are analogous to deception or to the, perhaps involuntary, transmission of misleading information.

Due to the mediation of social power, perceived expertise, and the ability to take up the role of main narrator of past events, the processes involved in memory convergence generate shared memories that are closer in content to the initial memories of the most powerful individuals in the group than to those of other members (Hirst and Echterhoff 2011). That is to say, the memories of individual group members tend to converge onto one version of the past which is profoundlly shaped by the original (self-serving) memories of dominant members.

Several mechanisms contribute to this outcome. There is evidence that perceived expertise, and especially the ability to assume the role of narrator, facilitate social contagion. These individuals can more easily than others spread their false or selective recollections to other members of the group (Brown, Coman and Hirst 2009). Explicit retrieval generates re-exposure effects that consolidate and strengthen the memories thus retrieved. Powerful individuals have better opportunities to recount their version of the past through public speaking. If their audiences covertly retrieve the same memories when listening, they are more likely to remember the facts in those terms. These effects are equally present in informal contexts. In addition, explicit retrieval generates SS-RIF effects. These are especially prominent when simultaneously 
listeners covertly retrieve the memories recalled by the speakers either because they identify with these individuals or, if they don't fully trust them, to monitor their words for accuracy. Therefore, narrators cause RIF effects in those who identify with them but also in those who are somewhat suspicious of their accuracy. ${ }^{28}$

In short, all of these mechanisms conspire to the creation of shared memories which converge in the direction of the recollections voiced by the most powerful members of the group. These can include false memories which have been deliberately or involuntarily implanted into the group as a whole. In addition, because of mnemonic silence manifested as lack of reexposure and as RIF effects the initial memories of marginalized group members become increasingly harder to retrieve. As absence of fluency is proxy for invalidity, these memories when retrieved are unlikely to be believed.

I have detailed how these processes generate states of ignorance. These are examples of strong memory ignorance because they are successes due to cognitive ability. They are achievements because they serve the practical needs of those narrators who have shaped the conversation about the group's collective past since they would rather have aspects of the past, which are not congruent with their self-concept or which they judge to be trivial, be forgotten. Ignorance in these instances is due to the cognitive abilities of all, including those individuals whose initial memories are being replaced with the memories recollected by others. These people are the audience to the speech of the narrators. It is their covert retrieval of memory representations that generates re-exposure and RIF effects; it facilitates fluency of further retrieval which in turn promotes endorsement as belief. The telling contribution in the creation of

\footnotetext{
${ }^{28}$ Those who don't pay attention and those who strongly disagree with the speakers are less prone to the same effects.
} 
successful ignorance is made by the cognitive abilities of the individual whose memories are shaped in these ways, since it is this contribution that leads to the endorsement of the false or misleading memories as valid.

The third kind of strong memory ignorance is due to the creation of memory environmental niches which increase the cognitive load required to find adequate answers to some non-trivial questions about the past. A memory niche is an aspect of one's surroundings that cues some memories and inhibits others. Many aspects of the built environment serve this scaffolding role. They include: street toponomy which singles out some individuals, events, or groups as worth remembering; monuments for the commemoration of special events (such as the Cenotaph); statues which memorialize distinguished historical figures (Nelson's column, for example); and commemorative ceremonies. ${ }^{29}$

These are among the mementoes for the whole of society. Their presence facilitates the implantation of false memories such as those surrounding the myths of the civilizing power of European colonizing empires. It consolidates some selective memories by virtue of re-exposure effects. Memorials to the war dead, for example, often portray heroism and sometimes horror. They rarely portray moments of weakness or despair which must have undoubtedly occurred. In this manner, they assist the retrieval of a selected range of representations of the people or events that they commemorate. Although current research on SS-RIF has focused exclusively on the retrieval-induced forgetting effects of remembering through conversation, it seems at least plausible that other cues for covert retrieval should have the same or similar effects. ${ }^{30}$ Hence,

${ }^{29}$ It is not only objects that serve as cues. Ritual ceremonies are equally important. They are the focus of Connerton (1996).

${ }^{30}$ This hypothesis is singled out by Stone and Hirst (2014) as an avenue for future research. 
monuments may consolidate shared memories of people and episodes that are highly selective. Because they may also inhibit the recollection of other, less flattering or convenient, aspects of the same individuals and events, they are misleading and facilitate the spread of ignorance. If this is right, memorials promote both memory and forgetting (cf. Connerton 2009, 29). It is therefore not surprising that political revolutions are often marked by the removal of cues memorializing aspects of the previous regime since this is an effective way of consigning it to oblivion.

Memorials are expensive to build and to maintain. They are generally commissioned by the state, powerful institutions, or rich individuals who are therefore able to determine which aspects of the past are remembered and the manner of their remembrance. This outcome is intended by those who have these monuments erected. Monuments are thus elements of niches promoting strong ignorance in the citizenry. They facilitate ignorance about some aspects of the past. This ignorance is a success since memorials are designed to memorialize but also to ignore some unflattering aspects of the past. The telling contribution to the achievement is made by the public whose memory is functioning well when it forms selective and misleading beliefs about its collective past.

\subsection{Intellectual Self-Trust, Collective Memories, Collective}

\section{Amnesia}

In section 10.5 I discussed the role of memory in the enhancement and preservation of selfesteem. In this section I pursue the topic further by arguing that collective memory and amnesia enhance the intellectual self-trust of some members of the community whilst undermining that possessed by others. 
For my purposes here, I adopt Karen Jones' account of intellectual self-trust as a cognitive and affective stance of optimism towards one's cognitive capacities in a given domain. This stance of optimism is characterized by confidence in one's own abilities, a belief in the reliability of one's cognitive faculties, a tendency to assert what one takes to be deliverances of one's methods, and a disposition to reflect on one's belief only when there is a genuine need to do so (2012) ${ }^{31}$ Intellectual self-trust is often self-enhancing. Those who trust their cognitive capacities use the same capacities to assess whether they can be trusted. ${ }^{32}$ Thus, independently of whether one's capacities are actually reliable, reliance on them may increase trust in their reliability. ${ }^{33}$ Further, intellectual self-trust is socially acquired. One learns to trust one's competence by being helped by others to improve one's cognitive performance and then by having the reliability of one's opinion confirmed by others one trusts.

Intellectual self-trust is, as Jones notes $(2012,245)$ sensitive to social power. Those who are in a position of power are likely to develop excessive optimism about their cognitive capacities in many domains because their power wins them deference. Since other people tend —out of fear, servility, or self-interest — to agree with them, socially dominant people form a false impression about the reliability and power of their cognitive capacities. This false belief in turn causes them to be unwarrantedly confident in their ability. Similar mechanisms in reverse lead people in subordinated positions to become exceedingly unconfident in their abilities. Thus, they may be

\footnotetext{
${ }^{31}$ Intellectual self-trust is appropriate only when one's cognitive capacities in the given domain are reliable and thus warrant optimism about them.

32 This circularity as Zagzebski (2012) has argued is unavoidable.

${ }^{33}$ Provided that their deliverances do not contradict one another.
} 
more distrusting of their capacities than the situation warrants. However, self-distrust works as a self-fulfilling prophecy since those who do not trust their abilities will develop timidity and intellectual servility, and become less capable as a result. ${ }^{34}$ Hence, power promotes the miscalibration of self-trust towards inflation in those who occupy positions of dominance and deflation in those who are subordinated.

Collective amnesia contributes to this phenomenon. I have argued that collective memories converge in the direction of the memories of the powerful. Whenever these memories are selfserving their adoption by the group as a whole functions to boost the intellectual self-trust of members of dominant groups. Even a short reflection on the representations of Black British people in contemporary collective memories of Britishness is sufficient to illustrate the point.

If you are not a member of a Black or Minority Ethnic community yourself, it is likely that the first representations of Black Britishness that come to mind represent Black people as a problem (Gilroy 1987). They are either victims of crime (Stephen Laurence), individuals whose presence in numbers undermines social cohesiveness (migrants in the 1950s or more recently), or finally people who engage in criminal behaviour (rioters and gang members). I presume that these memories have acquired prominence thanks to the memory mechanisms discussed above. These memories have the effect of decreasing self-confidence in those who are represented as problems. This dynamic is corrosive of self-trust in a further insidious way. Those, whose selfconfidence is undermined and who lose intellectual self-trust as a result, are more likely to perceive others as being their intellectual superiors. Since this perception facilitates social contagion of memories, the process is likely to consolidate memories that promote further self-

\footnotetext{
${ }^{34}$ On timidity and servility see Tanesini (2016 and Forthcoming).
} 
distrust; thus, they initiate and preserve a vicious circle that deflates the confidence of those who already distrust themselves and inflates the confidence of the overly confident.

\subsection{Memorial Injustice.}

Collective amnesia, I have argued, exacerbates miscalibrations of intellectual self-trust. In this section I argue that this dynamic is a distinct form of epistemic injustice. Epistemic injustice is 'a kind of injustice in which someone is wronged specifically in her capacity as a knower' (Fricker 2007, 20). Epistemic injustice is not a species of distributive injustice. Thus, it is not to be understood as the unfair distribution of epistemic goods. ${ }^{35}$ Rather, it is an injustice that one suffers when one is wronged because one is not treated in the way in which persons should be treated. The wrong is epistemic, and thus an epistemic injustice, when the ill treatment concerns the person qua epistemic agent; that is to say, it regards that person's cognitive capacities.

Respect and self-respect are important aspects of what it takes to treat other people and oneself in a manner consonant with personhood. There are, however, many forms of respect and self-respect. Fundamental among these are: evaluative, and recognition. Evaluative respect and self-respect are respect based on a proper evaluation of a person's (intellectual) qualities (Dillon 2007; Tanesini 2016) Hence, there is individual variance in the amount of evaluative respect which is due to one. Recognition respect and self-respect are respect based on the recognition that an individual is an (epistemic) agent. Recognition respect is due in equal measure to all agents. Recognition self-respect includes an unreflective attitude of appreciation of one's self-

\footnotetext{
${ }^{35}$ For this reason someone whose credibility is wrongly inflated may still be said to be suffering an injustice.
} 
worth. It is manifested in a sense of confidence in one's own abilities and value. Intellectual selftrust as I defined it above is one of the manifestations of recognition self-respect.

Different kinds of epistemic injustice can be distinguished by the kind of disrespect they exemplify. Testimonial injustice is a wrong because it is a lack of evaluative respect. In Fricker's account testimonial injustice is a credibility deficit due to identity prejudice $(2007,28)$. Those who are on the receiving of it are treated with less respect than they deserve given their personal intellectual qualities. Hermeneutical injustice is also a wrong because it results in a lack of evaluative self-respect. Hermeneutical injustice is often systematic so that there is not a specific behaviour by some individual which exemplifies it. Instead, it occurs when, because of identity prejudice, the epistemic community lacks the conceptual resources required to understand a significant area of experience of a group of individuals within it $(2007,155)$. Although no one in the community can understand fully this aspect of the experience of some of its members, only those whose experiences are thus obscured are aware that something important is missing. Because of their inability to articulate their experiences, and the presumptions that this is indicative of a lacuna on their part, they are likely to underestimate their intellectual abilities and thus develop lack of self-respect. ${ }^{36}$

The erosion of self-trust, which collective amnesia strengthens and perpetuates, undermines evaluative respect and self-respect; but, it also goes deeper because it affects recognition selfrespect. Intellectual self-trust is not a cognitive ability like any other; it is the stance of confidence towards one's abilities which is necessary if we are to exercise any one of them.

\footnotetext{
${ }^{36}$ It goes without saying that the wrong of this injustice is that those who suffer from it do themselves wrong as a result. This should not be read as saying that these individuals are culpable for their selfharm.
} 
Hence, if one were to lose all intellectual self-trust one would be totally incapacitated. One would be endlessly checking and re-checking the deliveries of one's cognitive capacities without feeling able to rely on them at all. Thus, without some degree of intellectual self-trust one would not be an epistemic agent. Consequently, erosion of self-trust undermines one's ability to treat oneself as any epistemic agent should treat herself. In this manner, those who are harmed in their capacity to self-trust are forced into a position in which they risk losing their recognition self-

respect. Therefore, to the extent to which cultural amnesia damages intellectual self-trust, it is the source of an especially pernicious form of epistemic injustice.

\section{References}

Bernecker, Sven. Memory: A Philosophical Study. Oxford: Oxford University Press, 2010.

Brown, Adam D., Alin Coman, and William Hirst. 'The Role of Narratorship and Expertise in Social Remembering'. Social Psychology 40, 3 (2009):119-29.

Coman, Alin, and William Hirst. 'Cognition through a Social Network: The Propagation of Induced Forgetting and Practice Effects'. Journal of Experimental Psychology: General 141, 2 (2012): 321-36.

Coman, Alin, David Manier, and William Hirst. 'Forgetting the Unforgettable through Conversation: Socially Shared Retrieval-Induced Forgetting of September 11 Memories'. Psychological Science 20, 5 (2009): 627-33.

Connerton, Paul. How Societies Remember. Cambridge: Cambridge University Press, 1996. Connerton, Paul. How Modernity Forgets. Cambridge: Cambridge University Press, 2009. Donald, Merlin. Origins of the Modern Mind: Three Stages in the Evolution of Culture and Cognition. Cambridge, MA: Harvard University Press, 1991. 
Dillon, Robin S. 'Arrogance, Self-Respect and Personhood'. Journal of Consciousness Studies 14, 5-1 (2007): 101-26.

Dotson, Kristie. 'Tracking Epistemic Violence, Tracking Practices of Silencing'. Hypatia 26, 2 (2011): 236-57.

Farkas, Katalin. 'Know-Wh Does Not Reduce to Know That'. American Philosophical Quarterly 53, 2 (2016): 109-22.

Fricker, Miranda. Epistemic Injustice. Oxford: Clarendon, 2007.

Gilroy, Paul. 'There Ain't No Black in the Union Jack': The Cultural Politics of Race and Nation. London: Hutchinson, 1987.

Greco, John. 'A (Different) Virtue Epistemology'. Philosophy and Phenomenological Research 85, 1 (2012): 1-26.

Hirst, William, and Gerald Echterhoff. 'Remembering in Conversations: The Social Sharing and Reshaping of Memories'. Annual Review of Psychology 63, 1 (2011): 55-79.

Hirst, William, and David Manier. 'Towards a Psychology of Collective Memory'. Memory 16, 3 (2008): $183-200$.

Jones, Karen. 'The Politics of Intellectual Self-Trust'. Social Epistemology 26, 2 (2012): 23752.

Kirsh, David. 'The Intelligent Use of Space'. Artificial Intelligence 73, 1-2 (1995): 31-68.

Koppel, Jonathan, Dana Wohl, Robert Meksin, and William Hirst. 'The Effect of Listening to Others Remember on Subsequent Memory: The Roles of Expertise and Trust in Socially Shared Retrieval-Induced Forgetting and Social Contagion'. Social Cognition 32, 2 (2014): $148-80$. 
Kunda, Ziva. ‘The Case for Motivated Reasoning'. Psychological Bulletin 108, 3 (1990): 48098.

Loftus, Elizabeth F. 'Planting Misinformation in the Human Mind: A 30-Year Investigation of the Malleability of Memory'. Learning \& Memory 12, 4 (2005): 361-6.

Marsh, Leslie, and Christian Onof. 'Stigmergic Epistemology, Stigmergic Cognition'. Cognitive Systems Research 9, 1-2 (2008): 136-49.

Martin, C.B., and Max Deutscher. 'Remembering'. Philosophical Review 75 (1966): 161-96.

Michaelian, Kourken. 'Is External Memory Memory? Biological Memory and Extended Mind'. Consciousness and Cognition 21, 3 (2012): 1154-65.

Michaelian, Kourken. Mental Time Travel: Episodic Memory and Our Knowledge of the Personal Past. Cambridge, MA and London: The MIT Press, 2016.

Michaelian, Kourken, and John Sutton. 'Distributed Cognition and Memory Research: History and Current Directions'. Review of Philosophy and Psychology 4, 1 (2013): 1-24.

Mills, Charles W. 'White Ignorance'. In Race and Epistemologies of Ignorance, edited by Shannon Sullivan and Nancy Tuana, 13-38. Albany: State University of New York Press, 2007.

Parent, T. 'Knowing-Wh and Embedded Questions'. Philosophy Compass 9, 2 (2014): 81-95.

Peels, Rik. 'What Is Ignorance?' Philosophia 38, 1 (2010): 57-67.

Peels, Rik. 'Ignorance Is Lack of True Belief: A Rejoinder to Le Morvan'. Philosophia 39, 2 (2011): 345-55.

Peels, Rik. 'The New View on Ignorance Undefeated'. Philosophia 40, 4 (2012): 741-50.

Pritchard, Duncan. Knowledge. Basingstoke: Palgrave MacMillan, 2009. 
Schacter, Daniel L. 'Constructive Memory: Past and Future'. Dialogues in Clinical Neuroscience 14, 1 (2012): 7-18.

Schacter, Daniel L., Joseph T. Coyle, Gerald D. Fischbach, Marek-Marsel Mesulam, and Lawrence E. Sullivan, eds. Memory Distortion: How Minds, Brains, and Societies Reconstruct the Past. Cambridge, MA: Harvard University Press, 1995.

Sedikides, Constantine, and Aiden P. Gregg. 'Self-Enhancement: Food for Thought'. Perspectives on Psychological Science 3, 2 (2008): 102-16.

Sosa, Ernest. A Virtue Epistemology. Apt Belief and Reflective Knowledge, Vol. I. Oxford: Clarendon Press, 2007.

Sterelny, Kim. 'Cognitive Load and Human Decision, or, Three Ways of Rolling the Rock Uphill'. In The Innate Mind Volume 2: Culture and Cognition, edited by Peter Carruthers, Stephen Laurence, and Stephen P. Stich, 217-33. Oxford: Oxford University Press, 2007. Sterelny, Kim. 'Minds: Extended or Scaffolded?' Phenomenology and the Cognitive Sciences 9, 4 (2010): 465-81.

Stone, Charles B., Alin Coman, Adam D. Brown, Jonathan Koppel, and William Hirst. 'Toward a Science of Silence: The Consequences of Leaving a Memory Unsaid'. Perspectives on Psychological Science 7, 1 (2012): 39-53.

Stone, Charles B., and William Hirst. '(Induced) Forgetting to Form a Collective Memory'. Memory Studies 7, 3 (2014): 314-27.

Sutton, John. 'Exograms and Interdisciplinarity: History, the Extended Mind, and the Civilizing Process'. In The Extended Mind, edited by Richard Menary, 189-225. Cambridge: MIT Press, 2010. 
Sutton, John. 'Scaffolding Memory: Themes, Taxonomies, Puzzles'. In Contextualizing Human Memory: An Interdisciplinary Approach to Understanding How Individuals and Groups Remember the Past edited by Lucas Bietti and Charlie B. Stone, 187-205. London: Routledge, 2016.

Sutton, John, Celia B. Harris, Paul G. Keil, and Amanda J. Barnier. 'The Psychology of Memory, Extended Cognition, and Socially Distributed Remembering'. Phenomenology and the Cognitive Sciences 9, 4 (2010): 521-60.

Tafarodi, Romin W., Tara C. Marshall, and Alan B. Milne. 'Self-Esteem and Memory'. Journal of Personality \& Social Psychology 84, 1 (2003): 29-45.

Tanesini, Alessandra. “'Calm Down Dear”: Intellectual Arrogance, Silencing and Ignorance’ Proceedings of the Aristotelian Society, Supplementary Volume XC, 2016

Tanesini, Alessandra. 'Intellectual Timidity and Servility, Journal of Philosophical Research, forthcoming.

Taraborelli, Dario. 'How the Web Is Changing the Way We Trust'. In Current Issues in Computing and Philosophy, edited by A. Briggle, K. Waelbers and P.A.E. Brey, 194-204. Amsterdam: IOS Press, 2008.

Tollefsen, Deborah P., Rick Dale, and Alexandra Paxton. 'Alignment, Transactive Memory, and Collective Cognitive Systems'. Review of Philosophy and Psychology 4, 1 (2013): 4964.

Tuana, Nancy. 'Coming to Understand: Orgasm and the Epistemology of Ignorance'. Hypatia 19, 1 (2004): 194-232.

Tuana, Nancy. 'The Speculum of Ignorance: The Women's Health Movement and Epistemologies of Ignorance'. Hypatia 21, 3 (2006): 1-19. 
Twenge, Jean M., and W. Keith Campbell. 'Self-Esteem and Socioeconomic Status: A MetaAnalytic Review'. Personality and Social Psychology Review 6, 1 (2002): 59-71.

van de Pol, Janneke, Monique Volman, and Jos Beishuizen. 'Scaffolding in Teacher-Student Interaction: A Decade of Research'. Educational Psychology Review 22, 3 (2010): 271-96.

Wegner D. M. 'Transactive memory: a contemporary analysis of group mind'. In Theories of Group Behavior, edited by B. Mullen and G.R. Goethals, 185-208. New York: SpringerVerlag, 1987.

Yamashiro, Jeremy K., and William Hirst. 'Mnemonic Convergence in a Social Network: Collective Memory and Extended Influence'. Journal of Applied Research in Memory and Cognition 3, 4 (2014): 272-9.

Zagzebski, Linda Trinkaus. Epistemic Authority: A Theory of Trust, Authority, and Autonomy in Belief. Oxford and New York: Oxford University Press, 2012. 